\title{
Recortes, fragmentos e intención patrimonial: "Materiales para un guión interpretativo de las iglesias del centro de Bogotá"
}

\author{
Fabián Andrés Llano ${ }^{1}$
}

\section{Introducción}

Plantear un itinerario cultural en Bogotá alrededor de la historia social de la vida religiosa supone inicialmente la elección de un recorrido que dé cuenta de su influencia en la consolidación de la cultura en Colombia. En términos de accesibilidad cultural y espacial, las iglesias del Centro Tradicional de Bogotá logran visibilizar este acopio cultural para disponerlo como un corredor turístico abierto donde se logren mezclar varios elementos a saber: las transformaciones urbanas, los cambios arquitectónicos, los cambios culturales con la influencia del arte religioso ${ }^{2}$, los debates políticos en relación con una moral laica versus una moral religiosa en los debates históricos entre la Iglesia y el Estado y sobre todo la influencia de la vida religiosa en la consolidación identitaria del bogotano.

Como relato de origen, el 6 de agosto de 1538, se ha convertido en una fecha memorable por la representación y simbolismo a que atañe. Nada más y nada menos que la conquista y la instalación de Gonzalo Jiménez de Quesada en nombre de Carlos V y el posterior bautizo de este territorio con el nombre de Nuevo Reino de Granada. Como emblema principal de la conquista se erigió la "capilla del Humilladero", ermita que fue emplazada en la plazuela de San Francisco con unas características muy simples: estaba construida y protegida con paja, tenía 12 pies de largo y 8 de ancho, pero sin duda fue la primera ermita de Bogotá que tuvo gran importancia.

Así construido, la ermita duro dos siglos hasta que en 1544 fue restructurado bajo otras técnicas y materiales; esta vez ya no estaría presente la paja sino que arribaría la teja y el ladrillo. Sin embargo estos materiales no fueron del todo resistentes y para 1591 el templo vería su nueva reestructuración. Con un gran predominio de la cultura eclesiástica en el

\footnotetext{
${ }^{1}$ Doctor en Ciencias Humanas del Patrimonio y la Cultura Universidad de Girona (España) Magister en Investigación social interdisciplinaria de la Universidad Distrital Francisco José de Caldas, Licenciado en Ciencias Sociales de la misma Universidad. En la actualidad se desempeña como docente investigador de la Universitaria Uniagustiniana. ID 0000-0003-2181-3476

${ }^{2}$ En cuanto al arte religioso, las alegorías fueron la principal técnica del arte religioso del siglo XIX. Las iglesias bogotanas fueron modelo permanente de los pintores nacionales en el siglo XIX, que sentían especial atracción por los campanarios. Igualmente, las iglesias y templos de Bogotá poseían numerosas imágenes religiosas, elaboradas en cerámica por artistas locales que los fieles veneraban con gran devoción. Pinturas y esculturas que en buena parte conservan las iglesias y museos Colonial y Santa Clara, ubicados en el Centro de Bogotá
} 
Nuevo Reino de Granada, la primera expulsión de los jesuitas en 1797, tendría un duro golpe, no solo en la administración de la salvación sino en los bienes que poseía.

No obstante, la influencia religiosa permanecería así como el trazo de la ciudad en la forma de damero español. Según Ángel Rama (1984), una de las formas de trasladar un orden social a una realidad física es precisamente a través de la fundación de las ciudades. Esto implicaba el previo diseño urbanístico mediante los lenguajes simbólicos de la cultura sujetos a concepción racional (...) el resultado en América Latina fue el diseño en damero, que reprodujeron (con o sin plano a la vista) las ciudades barrocas y que se prolongó hasta prácticamente nuestros días (p.6) Esta planeación de la ciudad colonial diseñada en damero bajo la unidad, planificación y orden riguroso que traducían una jerarquía social.

En este sentido, las supervivencias del pasado colonial y de las trazas arquitectónicas del periodo Republicano pueden rastrearse fácilmente desde las iglesias del centro tradicional. Las construcciones religiosas en Santafé, estaban ubicadas en lugares estratégicos. La Catedral por ejemplo, según los preceptos que regían la institución, se ubicaba en la Plaza Mayor, convirtiéndose en el símbolo de poder divino y a su vez localizada junto al poder político, que para la época de su construcción era el cabildo el ente gobernante. Sobre la llamada calle real a medida que la ciudad iba creciendo se iban edificando las iglesias de las distintas órdenes religiosas.

En el caso de los Franciscanos y los Agustinos se ubicaron al extremo norte de la ciudad. Posteriormente, sobre los nuevos límites norte y sur se instauraron las iglesias de las nieves y Santa Bárbara y hacia el occidente San Victorino. Por su parte las ermitas de Monserrate, Guadalupe, nuestra Señora de la Peña, Egipto y Belén, fueron construidas sobre antiguos templos Muiscas. También se edificaron claustros de las diferentes órdenes religiosas, que se localizaron exentos de la vía principal de la ciudad, generalmente los conventos de los curas hacia el oriente y los de las monjas al occidente (Atlas histórico de Bogotá, 1538-1910, p. 75).

La construcción de las iglesias en la antigua Santafé, tenía un orden estratégico que se configuró en una forma de protección a la ciudad. Las iglesias que existían en Bogotá a finales del siglo XIX, y que venían desde los primeros tiempos de la colonia, eran: la iglesia de San Ignacio, Santo Domingo. San Francisco, Nuestra Señora de la Concepción, nuestra Señora del Carmen, San Juan de Dios, San Agustín, Nuestra Señora de Las Nieves, Santa Bárbara, La Candelaria, La Capuchina, las Aguas, Santa Clara, Santa Inés, La Tercera, Voto Nacional Parroquia del Sagrado corazón de Jesús), San Diego, La Enseñanza ó Santa Gertrudis, Capilla de Nuestra Señora del Rosario, Capilla del Sagrario, La Iglesia-Panteón de la Veracruz, Belén, Egipto, Capilla de Monserrate, Capilla de Guadalupe (era republicana), Capilla de nuestra Señora de La Peña, Las Cruces (republicana), Capilla de los Ejercicios (republicana de Fin de Siglo), Capilla del Cementerio (republicana), capilla protestantes y San Victorino. (Historia de Bogotá, tomo 1, p. 201) 
Esta arquitectura ecléctica da cuenta no solamente del cambio del modelo espacial de ciudad, sino que además logra rememorar los sentidos y el deseo de modernidad que los bogotanos tenían en el cambio del siglo XIX al XX. En un rango histórico amplio, desde el periodo de la colonia hasta el presente, se puede llegar a consolidar un corredor turístico que muestre los cambios casi imperceptibles de la vida religiosa y las configuraciones identitarias de una ciudad que en sus primeros años de vida fue poco lo que logró transformarse ${ }^{3}$. Para el presente proyecto todas estas manifestaciones que hacen parte del espíritu del tiempo están presentes aún en los templos del centro de la ciudad.

En este orden de ideas, las iglesias del Centro Tradicional permiten una articulación con el concepto de itinerario cultural que permite la puesta en valor del significado y la autenticidad de estos valores arquitectónicos e históricos que suponen las iglesias del centro de la capital ${ }^{4}$. De este modo, el turismo cultural, entendido como apropiación social del patrimonio cultural, requiere de aspectos clave a la hora de elegir ciertos atractivos turísticos, que en este caso son patrimoniales: la accesibilidad cultural y la accesibilidad espacial. La primera hace referencia a la facilidad de interpretación por parte del turista o visitante respecto del atractivo propuesto, ya que para una buena puesta en valor de las iglesias se hace necesario una coherencia entre el discurso asociado a periodos y/o sucesos históricos y la ruta establecida.

Por otra parte la accesibilidad espacial, hace referencia a la parte interpretativa del recurso o atractivo cultural, pero desde la parte del desplazamiento y de la señalética. En el caso de las iglesias elegidas permite tener una ruta accesible, gracias a la cercanía entre ellas. Este texto no se centrará en el origen de las iglesias coloniales en Bogotá, más bien, su interés se centra en las transformaciones sociales y culturales, que permitió pensar en otro tipo de ciudad y en otras formas espaciales de renovación religiosa como lo fue el periodo conocido y reconocido por historiadores y arquitectos como la Republica ${ }^{5}$

\footnotetext{
${ }^{3}$ La Bogotá de principios del siglo XVII, fue una ciudad religiosa por excelencia. Los cambios urbanos en la ciudad solo se sintieron con fuerza luego de la modernización de la ciudad hacia 1950 con el antecedente inmediato de la tragedia del 9 de abril de 1948, sin embargo durante todo el siglo XIX afirmaciones y narraciones de los visitantes extranjeros, exponían su asombro al ver la cantidad de templos en la ciudad. Tal fue el caso de los franceses Boussingault y Roulin, quienes llegaron a Bogotá cuando esta comprendía lo que hoy llamamos el Centro Tradicional.

${ }^{4}$ Vale la pena mencionar que bajo este contexto, la vida religiosa de la época se estructuraba desde los ritos hasta los actos festivos. Del mismo modo que acontecía en la política, los feligreses atañían todo el triunfo independentista a toda clase de actos piadosos. Sobre la vida cultural de Bogotá, también se evidencia históricamente que los desfiles de carácter religioso eran los eventos más concurridos de Bogotá y todos tenían lugar en las principales calles de Bogotá, que para ese entonces se reducía a todo lo que hoy conocemos como el Centro Tradicional.

${ }^{5}$ De acuerdo con Pérgolis y Villar (2015) existe un acuerdo entre los arquitectos colombianos frente a la arquitectura desarrollada entre mediados del siglo XIX hasta 1930. Llamada también arquitectura ecléctica, la arquitectura republicana tuvo como característica la mezcla de estilos y procedencias. Esta arquitectura academicista se adopta en el contexto como representación del poder del edificio de gobierno con los signos y significados de una Europa ya pasada, es decir anacrónica bajo todo punto de vista para un contexto como el nuestro.
} 
En suma, un itinerario cultural construido con algunos referentes de la historia social de la vida religiosa desde la colonia hasta el periodo republicano, requiere identificar algunos puntos importantes en este recorrido. El primero de ellos es la influencia de la arquitectura y la pintura en la consolidación de un imaginario colonial amarrado a la devoción. En segundo lugar, las transformaciones urbanas que trajo consigo la modernización de la ciudad y con ello, la adecuación arquitectónica de las iglesias para entrar a los circuitos de la modernidad con la aplicación de una arquitectura ecléctica. En tercer lugar, el cambio de función de las iglesias desde la catequesis colonial al recorrido y la significación entre la vida contemplativa y la dinámica laboral que enfatizó el capitalismo en Bogotá.

\section{Arquitectura, cultura visual y espíritu del tiempo}

Las supervivencias de aquella ciudad colonial, que en otro tiempo fue escenario del desarrollo social y cultural de la Bogotá de arquitectura blanca y de casas vetustas, pueden ser rastreadas por la profusión de iglesias y el simbolismo espacial que en su momento representaron estas monumentales construcciones. Con un inventario de casas construidas con muros gruesos en adobe y grandes tejados diseñados con teja de barro, la arquitectura colonial permanece arraigada hasta finales del siglo XIX. Este tipo de arquitectura tuvo como escenario, las pilas y acueductos que generalmente aparecían en las plazas. En efecto, durante la colonia, la ciudad se proveía de los ríos Fucha, San Francisco, San Agustín y Arzobispo, de los que se derivaron pilas y acueductos que abastecían las casas aledañas a las plazas coloniales de Bogotá. Las pilas más importantes estaban en la Plaza Mayor, en Las Nieves y en San Victorino, a su vez había unos primitivos acueductos como el de Aguavieja y Aguanueva que cubrían el sector central.

Entre las capas históricas de un pasado que se resiste a desaparecer, se encuentran las huellas de un pasado indígena que centrados en una ética de la naturaleza ataban su existencia a los ciclos naturales. En un escenario de conquista, sumisión cultural y corporal convivió por algún tiempo, el desarrollo del hábitat urbano, con el hábitat natural. La vida en el siglo XIX seguía estando atada a los ciclos naturales donde los afluentes demarcaban el orden de la vida social ${ }^{6}$. Bajo este escenario, es interesante advertir con Saldarriaga y Fonseca (1989) que muestras de esa arquitectura permanecen hoy día bajo la representativa casa colonial. "La casa de zaguán y patio, de común construcción en Colombia durante el siglo XIX, fue

\footnotetext{
${ }^{6}$ La elección del sitio para fundar la ciudad se hace aplicando criterios que establecen cuales deben ser las condiciones naturales. El declive del terreno sirve para tener una visión del entorno que permita el control, al brindar amplias visuales. Las corrientes de agua valen como límites naturales y como murallas defensivas. Las aguas próximas se aprovechan para el uso doméstico y árboles y las tierras fértiles son requeridas para el abastecimiento de la población. Estos requisitos imprimen un viraje en la relación; las aguas interesan por ser objetos por explotar, para utilizar.Crf Carreira, A. (2007) De las perturbadoras y conflictivas relaciones de los bogotanos con sus aguas. Tabula Rasa n.6 Bogotá ene. /jun.
} 
otra muestra de esa herencia española, la que todavía está vigente en muchas regiones del país" (p. 181).

Con casas desplegadas horizontalmente en el espacio, era evidente la presencia del edificio colonial bajo la majestuosidad del orden divino. De expresión paleocristiana, con atrios doctrineros y en su mayoría naves únicas, los edificios coloniales tuvieron la intención y ocupación del territorio conquistado con el fin de ampliar la catequesis. Esta función espacial y simbólica de las ermitas y las iglesias coloniales además de buscar la conversión al catolicismo fueron sin duda un referente espacial que afectó la forma de percibir la realidad y la imaginería local. Según Pérgolis y Villar (2015) en el imaginario de la época, los edificios hacían parte de la aceptación de la institución como portadora de la verdad, confianza y seguridad; las capillas doctrineras como espacios cubiertos estaban abiertos para la catequización, pero no tenían una clara definición de un recorrido para unificar el interior de la vida religiosa y contemplativa con la vida exterior y secular, características posteriores de la arquitectura republicana.

En este orden de ideas, la sociedad colonial Neogranadina, amparada en una serie de mecanismos de reproducción y control social en cabeza de la conversión de indígenas alrededor de las enseñanzas del texto canónico y la profusión de un saber teológico que se fundamentó en la retórica y la lógica, proyectó no solo las certezas de un camino hacia la salvación del alma, sino que además logró la "naturalización" de prácticas religiosas bajo la figura del doctrinero, figura emblemática que se abrió paso con Felipe II en 1564 cuando ordenó acatar las determinaciones del Concilio de Trento para hacer frente a la iglesia protestante y fijar el dogma de la iglesia ${ }^{7}$. En este contexto de contrarreforma Según Renán Silva

la piedad y la devoción religiosas no fueron realidades ni inventadas, ni impuestas al grupo dominante, sino que se insertaban en las formas básicas constitutivas de este tipo de sociedad, incrustadas como "funciones naturales" (...) la función del dogma religioso y el uso del aparato eclesiástico con fines políticos contribuían al orden social (Silva, 2004 p.38).

Bajo la sustitución del paganismo indígena por el cristianismo, las capillas doctrineras resultaron un mecanismo eficiente para la propagación de la fe católica. Sin embargo, en el discurso, aquellas representaciones asociadas a lo indígena estuvieron estigmatizadas y asociadas con el valor nefasto de lo demoniaco. La asociación del demonio con los dioses indígenas persistió toda la colonia, pues aun en el siglo XVIII los escritores sostenían que Satanás se disfrazaba en ellos (Borja, 1998, p.196). Esto supuso, la consolidación de una política de la imagen donde confluyeran la palabra y la imagen. En los debates entre iconódulos e iconoclastas, la contrarreforma apostó en los contextos

\footnotetext{
${ }^{7}$ Los españoles argumentaban estar sirviendo a Dios y al rey, al mismo tiempo que se iba evangelizando, crecía el dominio de la corona española. La expedición que Gonzalo Jiménez de Quesada dirigió para llegar a Bogotá duro más de dos años, partiendo de Santa Marta en 1536.
} 
latinoamericanos por el sincretismo y la eficiencia de la imagen para esconder las diferencias culturales entre los ritos religiosos indígenas y católicos. A propósito de lo anterior, Gruzinsky (1990) desde el contexto mexicano se refiere al papel del teólogo tradicionalista, el dominico Alfonso de Montúfar en la reconversión de la aparición de la imagen de Guadalupe a la tradición católica.

El arzobispo había pedido a un pintor indígena, Marcos, una obra inspirada en un modelo europeo y pintada sobre un soporte de factura indígena, que hizo colocar discretamente en el lugar (o al lado) de la imagen primitiva. Efectuada en 1555, la sustitución, en apariencia carente de importancia, tuvo enormes consecuencias. Su instalación subrepticia le confirió el aura del misterio (y ¿por qué no del milagro?), ya que el prelado confirmó los prodigios asociados a la imagen y atribuyó el origen del culto al propio Jesucristo (p. 104).

Esta difusión de la imagen del culto mariano contrarreformada y territorializada en el antiguo santuario de Toci-Tonantzin, le valió a Montúfar la reforma del culto del Tepeyac y la diosa Tonantzin por el de la Virgen Cristiana

En esta nueva política de la imagen "al menos tres instituciones intervienen en la cuestión de las imágenes en el decenio de 1550: el Virrey, los pintores y la iglesia, y más si, en el seno de la iglesia, se distingue al arzobispo, los franciscanos y el concilio (Gruzinsky,1990 p.107).

La reconversión de las representaciones y cosmogonía indígena por las estructuras simbólicas del español estuvieron animadas por el posicionamiento de la imagen barroca (Gruzinsky, 1990; Borja 2003). Desde las determinaciones del Concilio de Trento se advirtió enfáticamente sobre la veneración y culto de las imágenes, en nuestro contexto, se insistió en el honor a lo que representaban bajo una política de la imagen que se desarrolló bajo tres presupuestos. Las verdades debían contener verdades dogmáticas, suscitar sentimientos de adoración e incitar a la práctica de la piedad, elementos contenidos en las prácticas pictóricas neogranadinas representadas en las vidas ejemplares de los santos, los mártires y la sagrada Familia como modelos sociales (Borja, 2003)

Las imágenes se transmitían visual o narrativamente, y su tratamiento se llevaba a cabo por medio de las técnicas retóricas (...) la retórica persuadía siguiendo tres objetivos; enseñar, deleitar y mover sentimientos; en otras palabras, se trataba de inducir a una causa mostrando vicios y virtudes (p167)

En un escenario como la Nueva Granada, la profusión de imágenes no se presentó como un espectáculo público administrado únicamente por el Estado. Esta tarea de elaboración de los enunciados pictóricos estuvo a cargo de la iglesia y los talleres de pintura Neogranadino del siglo XVII bajo un sistema de transmisión familiar y gremial en el que participaron Los Figueroa, los hermanos acero de la cruz, Gregorio Vásquez, Juan Francisco Ochoa y los hermanos Heredia(Borja, 2003, p168) 
Bajo estas circunstancias, las capillas se convirtieron en los lugares para perpetuar la imagen y la vida ejemplar de los santos. Los discursos sobre lo sagrado y las imágenes expuestas se asociaron para crear sentido. Esta significación entre logos e icono permitió un mayor control de las imágenes y las representaciones por parte de la institución eclesiástica. Lo importante aquí es entender, que estas disposiciones que hicieron parte del espíritu de la época (Zeitgeits) permanecen exhibidas aún en las iglesias del centro de Bogotá, pese a la disminución y zaqueo de muchas pinturas que desaparecieron con la expulsión de los jesuitas en diferentes momentos de la historia.

Finalmente, un recorrido que quiera incluir las visitas a las iglesias necesitará encerrar desde los guiones interpretativos estas significaciones y representaciones pictóricas para entender la cultura visual de esta época prolífica en producciones artísticas ${ }^{8}$. El escenario dispuesto para el recorrido mostrará no solo la influencia religiosa en Bogotá bajo la estructuración de los edificios coloniales (ermitas, iglesias) sino la sobrevivencia de las iglesias bajo la adaptación republicana y el deseo de modernidad

\section{Recortes y fragmentos sobre las iglesias republicanas}

Para tener una idea cercana del dominio religioso sobre la vida cotidiana en Bogotá hace falta únicamente recrear el reducido desarrollo urbano de la ciudad durante el siglo XIX. En efecto, la ciudad de Bogotá en el siglo XIX presentó un progreso lento desde el punto de vista del desarrollo urbanístico, sus límites seguían conservando la misma topografía colonial, donde la vida social se desarrollaba alrededor de la catedral y la plaza central,

El área poblada de la ciudad comprendía el terreno que se extiende entre las actuales calles $3^{\mathrm{a}}$ y 24 , de sur a norte y de la carrera $2^{\mathrm{a}}$ la 13 , de oriente a occidente. A lo largo de todo el siglo XIX, esta área urbana casi no creció a pesar que la población se quintuplico entre comienzos y finales del siglo como resultado de una utilización más intensiva del espacio urbano gracias a un paulatino achicamiento de nuevas casas construidas y, sobretodo, a la subdivisión de las ya existentes" (Fundación Misión Colombia 1988)

Con una ciudad pequeña de aspecto monacal que denotaba entre el cielo claro oscuro de Bogotá, las siluetas de los edificios coloniales, no existían barrios sino parroquias, una forma espacial de predominio de la pequeña Bogotá. A continuación se presentará una breve descripción sobre el espacio urbano de la época teniendo en cuenta las investigaciones de Germán Mejía Pavony desarrolladas en su libro los años del cambio historia urbana de Bogotá 1820-1910.

\footnotetext{
${ }^{8}$ Según el historiador Jaime Humberto Borja para la época se encontraban alrededor de 1.100 pinturas, donde se presentó un predominio de la representación de los santos con un total de 443 pinturas, seguido de las representaciones de la virgen con un total de 228 pinturas
} 
"Durante todo el siglo XIX, los bogotanos no cambiaron su forma de referirse al sector en que vivían como Parroquia.(...) De hecho, el concepto de Parroquia estaba tan arraigado, que las diferentes divisiones de la ciudad, en el orden administrativo, como las electorales y las de policía, salvo cortas excepciones, coincidieron o tomaron como principio de organización las zonas eclesiásticas hasta las décadas finales del siglo XIX. Así mismo, la Parroquia, fue la célula de división territorial del país hasta 1886, año a partir del cual, los distritos parroquiales comenzaron a ser conocidos como municipios (...) "Bogotá quedó así dividida en cuatro sectores desde mediados de los años 1830 hasta la década de 1880. La Catedral, Las Nieves, Santa Bárbara y San Victorino, fueron entonces parroquias para la iglesia y barrios para los gobernantes de la ciudad. De igual manera, en la medida en que los arrabales se iban consolidando y quedaban plenamente incorporados al casco urbano, adquirían la denominación de parroquia y barrio. Esto ocurrió con Egipto y Las Aguas en 1882. Algo similar sucedió, cuando en 1891 el Arzobispo dividió La Catedral en dos parroquias diferentes (...). Durante estos 62 años, tales sectores experimentaron una primera etapa de estancamiento, pues no se observa variación alguna en superficie, y luego, a partir de mediados de siglo, surge una segunda etapa en la que es apreciable un aumento en el área total que comprendían sus límites” (p. 306)

La Catedral emergió de la época colonial como la parroquia principal de Bogotá. Con centro en la Plaza Mayor, ella congregaba los edificios de gobierno y varios de los conventos e iglesias existentes en la urbe. Además allí se encontraban ubicados todos los almacenes, muchas de las viviendas de la aristocracia capitalina, y no menos importante, en ella tenía lugar el gran mercado semanal y todos los actos civiles y religiosos de trascendencia. Era así mismo, el sector mas extenso de la urbe. (...) El área de esta parroquia, incluyendo los extramuros en sus 74 manzanas demarcadas, era de 83,7 hectareas, lo cual representaba el 38\% del total de la superficie capitalina" (p. 308) "La parroquia Las Nieves, era la segunda en importancia de la ciudad. (...) En conjunto, 50 manzanas daban forma a La Nieves, lo que significaba un área de 56,6 hectáreas o el 26\% del total de superficie que tenía Bogotá en ese entonces" (309) "Santa Bárbara, tercera en importancia, estaba ubicada al sur de La Catedral y era en realidad una prolongación de esta última. (...) Además en esta parroquia se incluían dos pueblos de indios, llamados Teusaquillo (Santa Catalina) y Serbativá (en La Tolosa, adelante del Llano de Mesa). (...) Dentro de estos límites, 39 manzanas estaban trazadas en 1824, lo que representaba un área de 44, 1 hectáreas o el 20\% de la superficie de Bogotá” (p. 309)

La parroquia de San Victorino se extendía al norte y occidente de La Catedral. Al igual que Santa Bárbara, este sector era un suburbio de la parroquia central a comienzos del siglo XIX (...) La Plazuela de San Victorino y el paseo de la Alameda Nueva (o calle del Prado) eran los ejes de esta parroquia, la que adquiría su importancia al servir como puerto de entrada a la ciudad. Otra pequeña plazuela existía en este sector, la de la Capuchina, al frente del convento del mismo nombre y cuya iglesia se convirtió en parroquial al destruirse la antigua durante la década de 1820. En conjunto San Victorino tenía 32 manzanas demarcadas a comienzos del siglo XIX, lo que significaba un área de 36,2 hectáreas o el 16\% de la superficie de Bogotá”

Aunado al lento cambio en lo referente al espacio urbano, las obras de adecuación urbana como los acueductos también eran escasos. En la época de la república hubo grandes carencias en el abastecimiento de aguas en la ciudad. Durante todo el siglo XIX el hábitat urbano bogotano, careció de mecanismos suficientes de provisión de agua que lograran un 
completo abastecimiento para los ciudadanos de la urbe, estas adecuaciones, como por ejemplo los acueductos eran escasos, frenando de esta forma el suministro de tan necesario recurso en la vida cotidiana, además de esto, su construcción generalmente era lenta debido en gran medida a la falta de recursos necesarios para tal empresa. Las obras del acueducto y pila de San Victorino se continuaron en los comienzos del siglo XIX. Esta vez sí se culminarían las labores (...) la petición inicial de este acueducto se hizo en 1680, en 1792 se continuó la obra, y en 1801 se obtuvieron los dineros que permitirían concluirla en 1803 (Rodríguez, 2003, p 121).

\section{Según Chavarro y Llano (2010)}

Antes de procurar la expansión del territorio de la ciudad en los momentos en que se experimentaba algún aumento de población, se encaminaba a inaugurar mayor número de Iglesias, porque, se consideraba que el número de feligreses era demasiado para una sola parroquia. Veamos como describe uno de estos procesos Pedro María Ibáñez:

“Atendiendo a la extensión de las parroquias de la población, al aumento de la población y al deseo de entregar a la compañía de Jesús, encargada de la dirección del colegio nacional e San Bartolomé desde 1886, el templo de San Carlos, anexo al edificio del colegio, dispuso el señor Velasco, siguiendo lo prevenido en el Concilio de Trento, desmembrar parte del territorio de las parroquias de la Catedral, las Nieves y San Victorino, y erigir dos nuevas parroquiales en los templos de Veracruz y la capilla del Sagrario, con los nombres de San Pablo y San Pedro.” [Ibáñez: Op. Cit. 616]

Bogotá pese a las transformaciones que en ella se gestaban, como por ejemplo la fuerza racionalizante de la economía, no rompió de manera definitiva con la fuerza de los eventos públicos de carácter religioso, aquellos que se encontraban en capacidad de congregar a las diferentes clases en un mismo espacio físico y por tanto, espacio propicio para demostrar la distancia social que existía en la ciudad. Rosa Carnegie Williams, de origen inglés, quien acompañaba a su marido en un viaje de negocios describe de la siguiente manera la forma como se experimentaban en la cotidianidad la religiosidad, en el marco de la Semana Santa

“Algunas coronas que cargaba la gente eran verdaderamente hermosas. Resulta divertido ver a las damas con su sirvientes que extienden pequeños tapetes bordados sobre los cuales aquellas se arrodillaban para repetir las oraciones mientras observaban el movimiento de la incansable muchedumbre de palmas cruces y ramos, llevados por hombres y muchachos con las ruanas más sucias" [Carnegie Williams:1990:107]

En suma, con una vida religiosa dominante de la vida social desde los aspectos del nacimiento con el bautismo, hasta la muerte con el entierro inicialmente en las capillas y luego en el cementerio, las iglesias se consolidaron durante el siglo XIX, en el prototipo espacial y simbólico del ordenamiento territorial urbano. Sin embargo con el cambio de siglo y con la inserción de Colombia en la modernidad, la iglesia también asumió una actitud similar al deseo de modernidad, que Vivian particularmente los bogotanos. Con esto, se asumió las diferentes renovaciones de la arquitectura colonial para dar paso a la monumental 
arquitectura republicana, que se constituyó en una arquitectura ecléctica para recibir aquel deseo de modernidad característico del edificio público (Pérgolis y villar, 2015).

Con una iglesia acomodada a las nuevas circunstancias que trajo consigo el cambio de siglo, las procesiones, los rituales y sobre todo la resistencia para no desaparecer del escenario social, desde los debates educativos hasta los políticos, se hicieron cada vez más notables en el transcurso de la primera mitad del siglo XX. A continuación se presentará una descripción de las iglesias coloniales y las republicanas. Valga decir, que estas construcciones han sufrido varias transformaciones y cambio de estilo y otras aunque cambiaron decidieron volver a sus funciones fundamentales.

\section{Referencias}

Achugar, H.1999. El lugar de la memoria. En cultura y globalización Comp: Barbero Jesús Martín. Universidad Nacional de Colombia.

Agamben, G. (2011) infancia e historia, ensayo sobre la destrucción de la experiencia, editorial Adriana Hidalgo, Argentina

Anderson, B. [1983]. Comunidades imaginadas: reflexiones sobre los orígenes y difusión del nacionalismo.

Augé M, (2008) el viaje imposible el turismo y sus imágenes editorial Gedisa, Barcelona España

Augé M. (1993) Los no lugares. Espacios del anonimato para una antropología de la sobremodernidad. Gedisa editorial, Barcelona España, Pág. 125

Benjamín, W.2009 sobre el concepto de la historia en: estética y política. Editorial la cuarenta, ciudad autónoma de Buenos Aires

Borja, J. (1998) Rostros y rastros del demonio en la Nueva Granada. Indios, negros, judíos y otras huestes de Satanás. Editorial Ariel, Santa fé de Bogotá

Borja, J. (2003) Discursos visuales: retórica y pintura en la Nueva Granada. En: Balance y desafíos de la historia de Colombia al inicio del siglo XXI. Homenaje a Jaime Jaramillo Uribe. Comp. Adriana Maya Restrepo, Diana Bonnett Vélez, ediciones Uniandes

Bourdieu, P. 1999 Efectos de lugar en La miseria del mundo. Fondo de cultura económica México.

Chavarro, C. \& Llano, F. (2010). El héroe, el lujo y la precariedad patrimonio histórico en Bogotá (1880-1950). Bogotá: Universidad La Gran Colombia.

Fisher T. 1999. La gente decente en Bogotá Estilo de vida y distinción en el siglo XIX Visto por viajeros extranjeros en revista colombiana de Antropología. Vol 35-39 
Fundación Misión Colombia [1988] Historia de Bogotá. Volumen III. Villegas Editores. Bogotá.

Gruzinski S. (1990) la guerra de las imágenes de Cristóbal Colón a Blade Runner" (14922019) Fondo de Cultura Económica, México

Instituto Distrital de Patrimonio cultural (2014).La Paz y el Sagrado Corazón: Iglesia del Voto Nacional.

Iriarte A. 1988 Breve historia de Bogotá. Editorial Oveja Negra. Fundación Misión Colombia.

Llano, F. (2014). Espacios olvidados, lugares diferenciados: transformación social del espacio urbano en Bogotá (1850- 1880) Revista Nodo Universidad Antonio Nariño

Llano, F. (2012). Caro, Cuervo y la resistencia linguiística. Construcción de la identidad ciudadana, desde el uso de la lengua. Bogotá (1880-1950). Bogotá: Universidad La Gran Colombia.

Martínez, F. 2000 ¿cómo representar a Colombia? De las exposiciones universales a la exposición del centenario 1851- 1910 en: museo, memoria y nación, misión de los museos nacionales para los ciudadanos del futuro; Gonzalo Sánchez Gómez, María Emma wills Obregón compiladores

Mejía Pavony, G. [1988]. "Bogotá condiciones de vida y dominación a finales del siglo diecinueve". En: Boletín de historia. Vol. 5. Bogotá. Colombia.

Mejía, G. (1999) Los años del cambio. Historia urbana de Bogotá (1820-1910) pontificia Universidad Javeriana Facultad de Ciencias Sociales.

Melo, J. [1991]. La República conservadora. En Colombia Hoy perspectivas hacia el siglo XXI. Siglo XXI editores. Bogotá

Pérgolis J. Villar M, (2015) Arquidiócesis, arquitectura y espíritu del tiempo: entre la representación y la significación En: Arquidiócesis de Bogotá 450 años. Miradas sobre su historia, arquidiócesis de Bogotá, Universidad Santo Tomas.

Rama, A. (1984) La ciudad letrada. Hanover, Ediciones del norte.

Rueda L. 2012. La paradoja del monumento histórico o de la demolición del antiguo convento de Santo Domingo en Santafé de Bogotá. 1939-1947. En Anuario de Historia Regional y de las Fronteras, Volumen 17-1

Salazar, M. 2010. Lugares dentro de lugares. El rito de la memoria en la composición arquitectónica. Centro cultural Jorge Eliecer Gaitan: Rogelio Salmona. Universidad Nacional

Serna A. 2001 Próceres, textos y monumentos: culturas urbanas, discursos escolares y formas de la historia: Bogotá [1938-1991] Univ. Del bosque facultad de educación.

Silva, R. (2004). Saber, cultura y sociedad en el nuevo reino de Granada siglos XVII y XVIII, la carrera editores E.U. Medellín 
